\title{
Development of flow-accelerated corrosion prediction method (2) Modeling and validation with thinning rate profile data
}

\author{
Kimitoshi YONEDA*, Kazutoshi FUJIWARA*, Ryo MORITA* and Fumio INADA* \\ ${ }^{*}$ Central Research Institute of Electric Power Industry \\ 2-6-1 Nagasaka, Yokosuka, Kanagawa 240-0196, Japan \\ E-mail: yone@criepi.denken.or.jp
}

Received: 15 August 2017; Revised: 10 November 2017; Accepted: 4 December 2017

\begin{abstract}
A series of study is presented to develop a prediction method for pipe wall thinning in power plants in order to improve the maintenance management for piping system. In the first report, experiments for flow-accelerated corrosion (FAC) of carbon steel specimens were conducted and basic data of FAC rate were obtained by setting temperature from 50 to $150{ }^{\circ} \mathrm{C}$ and $\mathrm{pH}$ from 7.0 to 9.8 as main parameters. As this second report, the experimental data of FAC rate were compared with the prediction method. Effective mass transfer coefficient correlation was proposed and implemented into the prediction method considering combining effect of local average and turbulent velocity in the near-wall region calculated by computational fluid dynamics (CFD) simulation code. Fairly good agreement was confirmed between experimental and predicted FAC rate profile, quantitatively. Continuously, prediction method was applied to actual power plant piping systems, and some elbow components were chosen for evaluation in detail. Comparison of measured and predicted FAC rate also showed good agreement with data mostly evaluated conservatively in sense of maintenance management. As a whole, presented FAC prediction method including effective mass transfer coefficient was confirmed to predict measured FAC rate data of power plant pipe component with fairly good accuracy and reasonable conservatism, at least for the subjected temperature and $\mathrm{pH}$ conditions.
\end{abstract}

Keywords : Pipe wall thinning, Flow-accelerated corrosion (FAC), Thinning rate, Mass transfer coefficient

\section{Introduction}

For the stable operation and maintaining integrity of power plants, pipe wall thinning is one of the important issues to be managed. Especially, Flow-Accelerated Corrosion (FAC) requires thorough attention with continuous care for its potential of catastrophic ruptures of large diameter pipes in main piping systems, as seen in Surry (U.S.NRC,1986) and Mihama (NISA, 2004). In Japan, technical management rules for pipe wall thinning have been established after the Mihama accident based on thinning rate and residual lifetime evaluation relying on pipe wall thickness measurement results, for the use in boiling water reactors (BWR), pressurized water reactors (PWR), and fossil plants, and recently revised (JSME, 2017a, 2017b, 2017c). With wall thickness measurement data, thinning trend at each component can be evaluated, individually. In addition, when more than three measurement data obtained in different outages are available, thinning rate would be calculated with least-square method and the management can be conducted with a certain accuracy and proper conservativeness.

However, this may result in enormous number of measurements for each outage in power plants, and in partial, there are some elements evaluated excessively conservative that may be forced to replace much earlier than their essential residual lifetime. On the contrary, there are problems for components whose thickness is hard to be quantified with ordinary measurement tools due to its geometric restriction or in lack of reliable measurement data. In addition, some inconvenience may occur when plant operation condition changes since present management is basically assuming constant operation condition resulting constant thinning rate, normally. For example, water chemistry treatment shift to 
high pH condition in PWR plants may generally decrease FAC rate and extend residual lifetime of piping longer than with former $\mathrm{pH}$ condition. Another example is power uprate assumable in the future in Japan which may increase flow rate in some pipelines and conversely lead to lifetime shortening with FAC rate increase. However in either case, as long as the least-square method with measurement data is applied, the following measurement schedule cannot be set rationally since measurement data obtained before condition change should be taken into account in the lifetime evaluation in the present rule.

For future improvement of the pipe wall thinning management in Japanese power plants, introduction of prediction method and code for thinning rate and residual lifetime evaluation is expected, while in other countries, several codes or software are already utilized in their plant piping management (Chexal, 1999, Zander, 2003, Persoz, 2006, Tomarov, 2002). Applying such code assured with valid accuracy and reliability, most of the abovementioned problems would be solved or more relaxed than before.

The authors have been conducting researches to develop pipe wall thinning prediction method for the use in domestic power plants. At first, fundamental data from original experiments and related numerical simulations were obtained, followed by the equation modelling to predict the thinning rate based on thinning phenomena mechanism. After validating with experimental and power plant data, the prediction model was finally installed into an in-house prediction software developed for the management in domestic power plants, followed by further improvement and renewals of the model and the software. A series of paper will be presented for each step in this developing process. In the previous first report, FAC experiments of carbon steel specimens were conducted and basic data of FAC rate were obtained by setting temperature and $\mathrm{pH}$ as main parameters (Yoneda, 2016). In this second report, local FAC rate profile on test specimens and in piping components are compared with the prediction method. In this process, the key technique is the evaluation of mass transfer coefficient depending on flow features in near-wall region since FAC is known to be driven by the mass transfer of ferrous ion from oxide surface to bulk water.

Although the studies of FAC, or formerly called “erosion corrosion” before the definition of FAC (EPRI, 1996), were conducted from around 1970's, not much publications were found for mass transfer coefficient evaluation in the early days. In this situation, Berger and Hau (1977) proposed a mass transfer coefficient correlation for fully-developed flow in straight pipe which strongly stood out and is still widely referred to in this field. The correlation consisted of power law with two non-dimensional numbers; Reynolds number and Schmidt number which will be explained in detail in the next chapter. Since FAC phenomena occur in pipe components other than straight pipes, modelling of mass transfer was performed for specific geometries such as orifice (Berger \& Hau, 1977, Tagg, 1979) or elbow (Wang, 2001), and many other conditions (reviewed by Schmitt, 2008). In most of these cases, the correlation was also expressed in terms of Reynolds and Schmidt number, however the exponents and coefficients were defined specifically only for the subjected geometry and condition. Recently, with the development of commercial computational fluid dynamics (CFD) codes, several evaluations of mass transfer coefficient profile in pipe components were conducted by the aid of CFD codes. Ahmed (2012) and El-Gammal (2012) calculated turbulent flow in orifice in conjunction with the species transport equations of ferrous ions using CFD code. Lin (2014) evaluated mass transfer coefficient in elbow by combining oxygen diffusion process from bulk flow to wall. Rani (2014) calculated mass transfer coefficient based on CFD simulation results of wall shear stress. Utanohara (2013) also focused on wall shear stress and obtained reasonable relation with FAC rate by evaluating its RMS values through unsteady large eddy simulation (LES).

The authors aim to apply prediction method to several cases of large scale piping in power plants, including various types of pipe components, which may require considerable computational resource for turbulent flow calculation. Hence unsteady-state simulations or/and complicated evaluation would be inefficient and not applicable, and instead, simplified and universal evaluation method with steady-state by CFD code would be favorable. In addition, mass transfer coefficient should be validated by implementing into FAC prediction model. Consequently in this report, by referring to previous studies, modeling of mass transfer coefficient correlation was discussed based on steady-state CFD code calculation, following by the validation with FAC rate data from experiment and power plant piping.

\section{Modeling of mass transfer coefficient correlation 2.1 FAC prediction model}

In this study, FAC prediction model proposed by Fujiwara (2011a) is implemented for validation with FAC rate data. 
The model equation for FAC rate (TR) is consisted of the product of mass transfer coefficient $k_{M}$, solubility of iron ( $\left.S_{F e}\right)$, and chromium effect including parameter $\theta$ as surface ratio of chromium oxide, where each basically stands for hydraulic, water chemistry and material factors, respectively, and expressed as shown in Eq. (1).

$$
\mathrm{TR}=k_{M} S_{F e}(1-\theta)
$$

This model was constructed based on the following assumptions; (a) constant wall thinning phenomena, (b) oxide layer mainly consisted of Magnetite $\left(\mathrm{Fe}_{3} \mathrm{O}_{4}\right)$, (c) constant properties of oxide layer such as thickness and porosity, (d) existence of saturation layer on the surface of oxide layer, and (e) diffusion controlled phenomena in the boundary layer. In addition, effect of dissolved oxygen (DO) on FAC is not considered in this paper since condition with very low DO level, below 1 ppb, is only dealt, although the effect is considered in the original model.

Evaluation example of iron solubility is shown in Fig. 1 which is based on the calculation by Fujiwara (2011b). The solubility differs considerably between neutral and alkaline $\mathrm{pH}$ condition, and the trend shows a peak in terms of temperature.

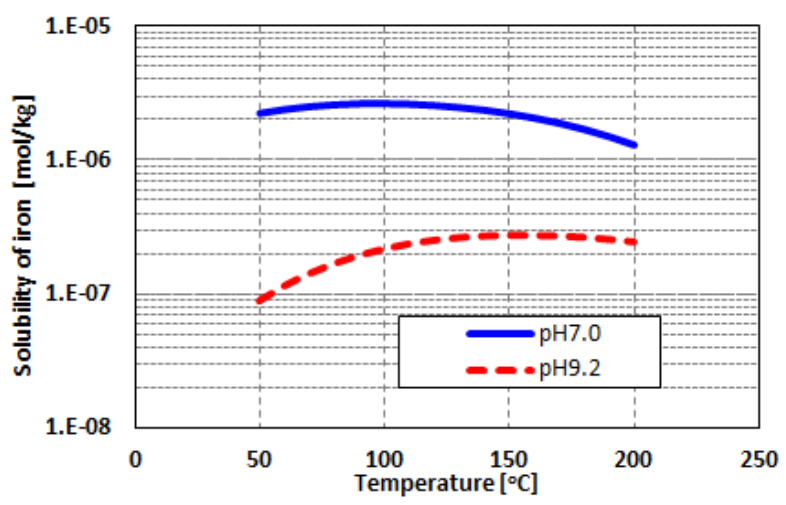

Fig. 1 Solubility of iron in terms of temperature

Chromium effect parameter $\theta$ is defined with solubility $S$, atomic weight $M$, and content ratio in base metal $X$ for chromium ( $\mathrm{Cr}$ ) and iron (Fe) as expressed in Eq. (2) and its trend is shown in Fig. 2. FAC rate decrease exponentially with chromium content and this tendency appears with less content in lower pH condition. In terms of temperature, slight different can be seen with a bottom.

$$
\theta=\left[1+\frac{s_{C r} M_{C r} / X_{C r}}{S_{F e} M_{F e} / X_{F e}}\right]^{-1}
$$

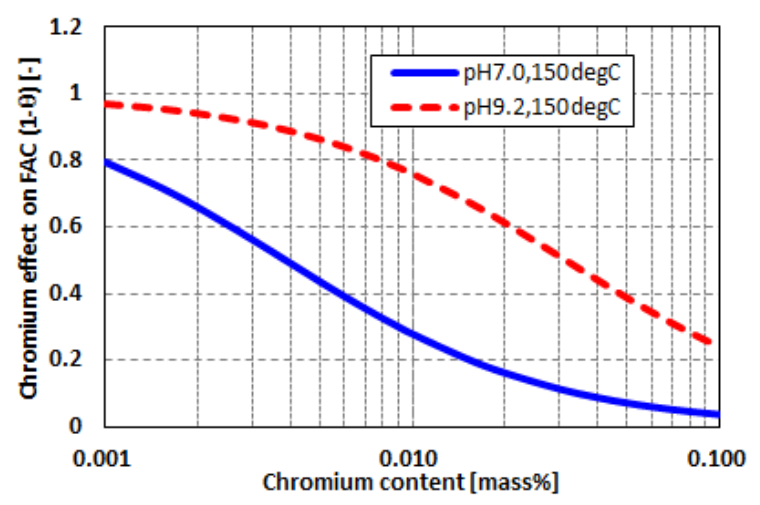

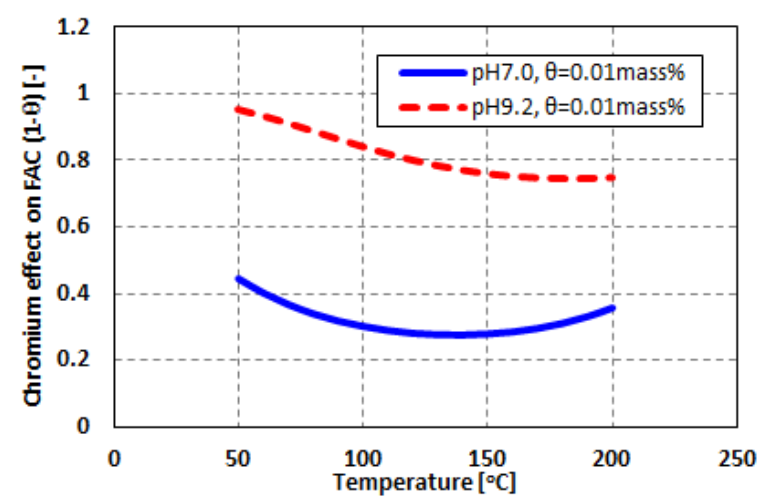

Fig. 2 Evaluation of Chromium effect on FAC

Applying above iron solubility and chromium effect, FAC rate can be evaluated by implementing mass transfer coefficient discussed in the following section. In the evaluation of mass transfer coefficient, diffusivity of iron soluble is included which also considers the effect of water chemistry. In this study, diffusivity model proposed by Fujiwara (2017) is applied which considers existing ratio of iron soluble species; $\mathrm{Fe}^{2+}, \mathrm{Fe}(\mathrm{OH})^{+}, \mathrm{Fe}(\mathrm{OH})_{2}$. The trend is shown in Fig. 3 
with monotonic increase in terms with temperature.

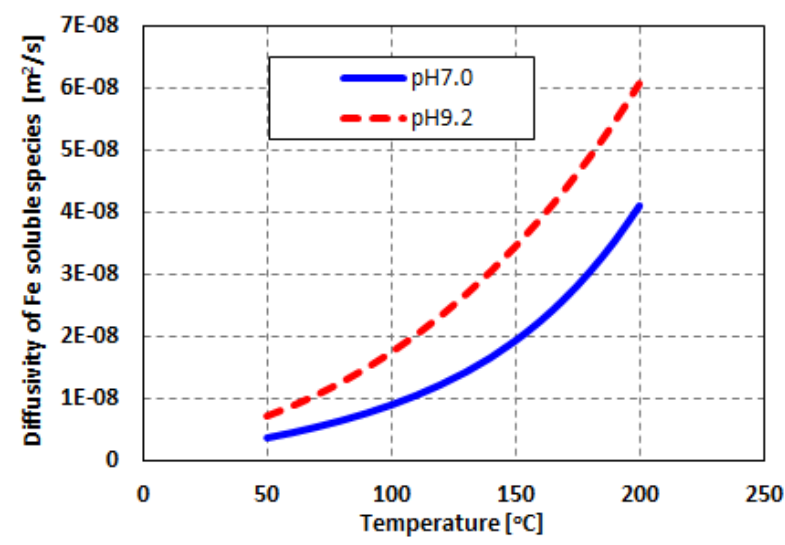

Fig. 3 Evaluation of Diffusivity or iron soluble species

\subsection{General equations related to mass transfer coefficient}

In this section, general equation of mass transfer coefficient will be presented with the knowledges of previous studies. To evaluate mass transfer in a pipe or a duct with fully-developed turbulence, analogy of heat and mass transfer by Chilton and Colburn (1934) is often used for its broad applicability. With this analogy, non-dimensional parameters for mass transfer are related with pipe friction factor $f$, as follows,

$$
\frac{f}{2}=\frac{\operatorname{Sh}}{\operatorname{ReSc}^{0.33}}
$$

where Sh is Sherwood number, Re is Reynolds number, and Sc is Schmidt number. Sherwood number is defined with mass transfer coefficient $k_{M}$, pipe diameter $d$, and diffusivity $D$ as in Eq. (4).

$$
\operatorname{Sh}=\frac{k_{M} d}{D}
$$

Combining Eqs. (3) and (4), mass transfer coefficient can be expressed as below.

$$
k_{M}=\frac{f}{2} \operatorname{ReSc}^{0.33} \frac{D}{d}
$$

If well-known Blasius’ friction factor is applied for the pipe friction factor for example, mass transfer coefficient may be expressed as follows.

$$
\frac{f}{2}=\frac{1}{8} \times 0.3164 \mathrm{Re}^{-0.25}, k_{M}=0.0396 \mathrm{Re}^{0.75} \mathrm{Sc}^{0.33} \frac{D}{d}
$$

As in Eq. (6) or previous studies referred to in the former chapter, mass transfer coefficient correlation can be written generally in the form of Eq. (7),

$$
k_{M}=a \operatorname{Re}^{\alpha} \operatorname{Sc}^{\beta} \frac{D}{d}
$$

where $a$ is the constant, $\alpha$ and $\beta$ are exponents for Reynolds and Schmidt number, respectively.

Pipe friction factor can be related with mean velocity $U_{m}$ and friction velocity $U_{\tau}$ in the pipe from its definition.

$$
\frac{f}{2}=\frac{\tau_{w}}{\rho U_{m}^{2}}=\left(\frac{U_{\tau}}{U_{m}}\right)^{2}
$$


When assuming $1 / n$ power law for velocity distribution in fully-developed turbulence flow, mean velocity can be related with friction velocity by integrating velocity profile in radial direction as follows,

$$
U_{m}=N C\left(\frac{d}{2 v}\right)^{\frac{1}{n}} U_{\tau}^{\frac{n+1}{n}} \quad\left(N=\frac{2 n^{2}}{(2 n+1)(n+1)}\right)
$$

where $v$ is kinematic viscosity and $C$ is a specific constant according to $n$ as shown in Fig. 4 (JSME, 2006). The index $n$ is set from 7 to 10 corresponding to Reynolds number condition from the order from about $10^{4}$ to $3 \times 10^{6}$, and constant $C$ accordingly vary as well. For higher Reynolds number condition, $n$ and $C$ would be valid to increase by extrapolating the presented trend.

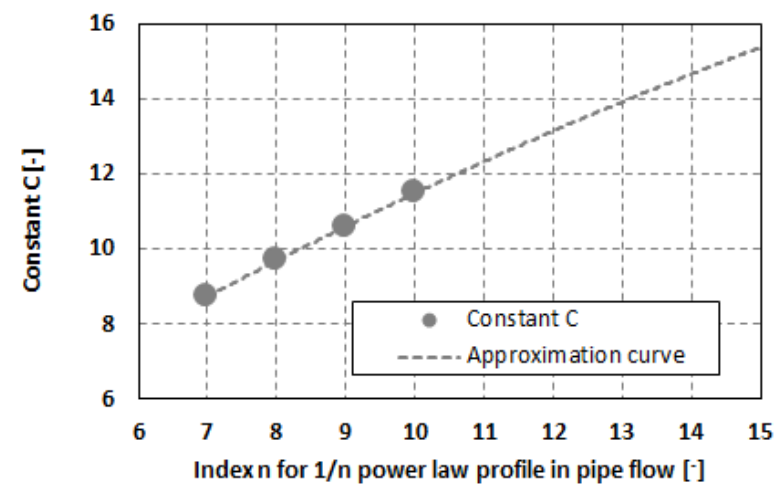

Fig. 4 Constant $C$ for $1 / n$ power law velocity profile

From Eqs. (7) and (9), general relation between mass transfer coefficient and friction velocity can be derived as in Eq. (10) which shows direct relation of mass transfer and velocity profile near the wall region.

$$
k_{M} \propto \operatorname{Re}^{\alpha} \propto U_{m}^{\alpha} \propto U_{\tau}^{\alpha \frac{n+1}{n}}
$$

\subsection{Effective mass transfer coefficient}

In this section, mass transfer coefficient correlation is discussed which can be applied to eccentric flow condition in pipe components such as elbows or orifices by focusing on friction velocity. Friction velocity is normally defined with the slope of local mean velocity profile $d U / d y$ at wall.

$$
U_{\tau}=\sqrt{\left.v \frac{d U}{d y}\right|_{\text {wall }}}
$$

In case of eccentric flow with high velocity at near-wall region, the slope $d U / d y$ would be larger, compared to the fullydeveloped turbulent condition. In addition, with high turbulence, relatively large fluctuation velocity component, the local turbulent velocity $U^{\prime}$, will overlap on mean velocity $U$. To evaluate this specific situation, a simple idea of adding the turbulent velocity $U^{\prime}$, multiplied by a constant figure, to the mean velocity $U$ at wall was introduced. Consequently, the effective friction velocity $U_{\tau e}$ was proposed and defined by the following equations (Yoneda 2013), so as to apply for local mass transfer coefficient of near-wall region for eccentric flow,

$$
\begin{aligned}
& U_{\tau e}=\sqrt{v \frac{U_{e}}{y_{1}}} \\
& U_{e}=\left|U_{1}\right|+c_{t 1}\left(U_{1}^{\prime}-c_{t 2}\left|U_{1}\right|\right) \quad\left(c_{t 2}=\frac{U_{10}^{\prime}}{U_{10}}\right)
\end{aligned}
$$

where $U_{e}$ is effective velocity for effective friction velocity, subscript 1 stands for the first calculation mesh on wall surface in CFD simulation and 0 for fully-developed turbulent flow. Constant $c_{t 1}$ is intensity factor to amplify the effect 
of flow fluctuation, and $c_{t 2}$ is aimed to cancel the effect equivalent to fully-developed turbulent condition. Both constants would depend on turbulent model utilized in CFD simulation; $c_{t 1}$ would be optimized considering the balance of mean and turbulent velocity in eccentric flow condition, $c_{t 2}$ would be determined through simulation for fully-developed turbulent flow. It should be noted that this equation is only effective at the wall surface. Consequently, to obtain a valid velocity profile slope for the equation, the data of $U$ and $U$ ' in viscous sub-layer must be referred to, where wall distance and axial velocity are in proportional relation, universally.

With the ratio of effective friction velocity to friction velocity for fully-developed turbulent flow and Eq. (10), effective mass transfer coefficient $k_{M e}$ for eccentric flow condition can be derived as follows.

$$
k_{M e}=\left(\frac{U_{\tau e}}{U_{\tau 0}}\right)^{\alpha \frac{n+1}{n}} k_{M 0}
$$

In this evaluation process, the value of exponent $\alpha$ would be very important in model validation. By replacing $k_{M}$ with $k_{M e}$ in Eq. (1) and considering Eq.(7), element representing hydraulic effect on FAC rate prediction model can be extracted where exponent $\alpha$ is only related. Based on Eq. (16), $\alpha$ would be derived through comparison of experimental FAC rate to CFD simulation.

$$
\begin{aligned}
& \mathrm{TR}=k_{M e} S_{F e}(1-\theta) \\
& \mathrm{TR}=\mathrm{a}\left[S_{F e}(1-\theta) \mathrm{Sc}^{\beta}(D / d)\right]\left[\operatorname{Re}\left(\frac{U_{\tau e}}{U_{\tau 0}}\right)^{\frac{n+1}{n}}\right]^{\alpha}
\end{aligned}
$$

\section{Model validation with experimental data 3.1 CFD calculation model and condition}

To evaluate mass transfer coefficient profile for the FAC experiment in vertical rectangular flow duct geometry in the previous report (Yoneda, 2016) as shown in Fig. 5, numerical calculations for steady-state flow were conducted with commercial CFD code STAR-CCM+ Ver.11 developed by CD-adapco. Basic equations of continuity and momentum conservation were solved with finite-volume scheme and SIMPLE (Semi-Implicit Method Pressure-Linked Equation) method as discretization procedure and analytical approach, respectively. Realizable k- $\varepsilon$ two-layer model was utilized as turbulent model. Analytical performance of the model in this CFD code was validated by Watanabe (2013) using flow field measurement data in elbow piping (Shiraishi, 2006). Polyhedral mesh was applied to the calculation mesh as shown in Fig. 6. Prism layer is installed along the wall surface with 10 layers in about $0.4 \mathrm{~mm}$ which set the first cell center at $1.6 \mu \mathrm{m}$ from the wall where non-dimensional wall distance $y^{+}\left(=U_{\tau} y / v\right)$ would be less than 2.0 within the range of viscous sub-layer. Calculation mesh was extended $200 \mathrm{~mm}$ in upstream and $300 \mathrm{~mm}$ in downstream from the contraction. Number of cells was about 2.1 million. Calculations were performed with temperature condition at $150{ }^{\circ} \mathrm{C}$, and with three inlet uniform velocity conditions (V); $4.5 \mathrm{~m} / \mathrm{s}, 3.0 \mathrm{~m} / \mathrm{s}$ and $1.5 \mathrm{~m} / \mathrm{s}$. Non-slip condition was set for all wall boundaries. Reference calculations were also conducted for flow duct without contraction to evaluate the values of $c_{t 2}$.

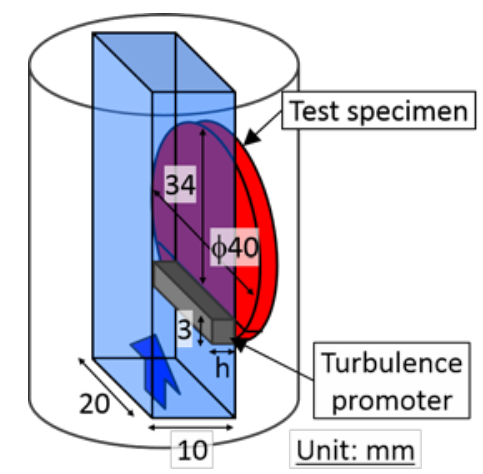

Fig. 5 Schematic of vertical rectangular flow duct for FAC experiment 


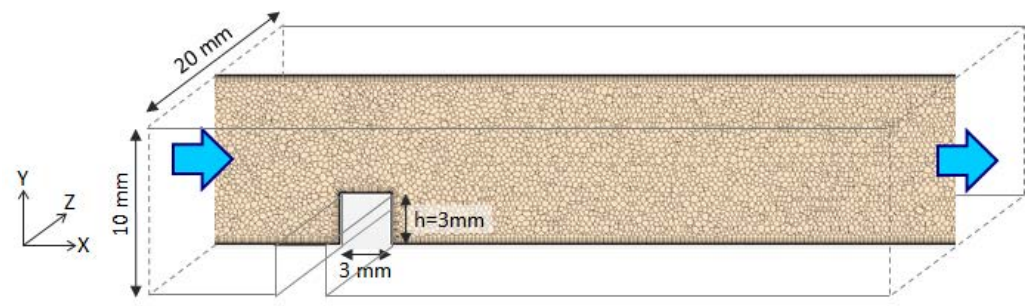

Fig. 6 Portion of CFD calculation mesh for FAC experiment test section (Sliced section at flow duct center around the contraction)

In the following section, calculated data at the first cell on the wall surface at flow duct center would be extracted and processed for mass transfer coefficient evaluation. Mean and turbulent velocity, $U_{1}$ and $U^{\prime}{ }_{1}$ in Eq. (13), were derived with calculated data with the definition below,

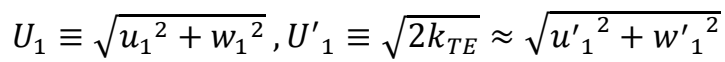

where $u_{1}$ and $w_{1}$ are mean velocity, $u_{1}{ }_{1}$ and $w^{\prime}{ }_{1}$ are turbulent velocity in $\mathrm{x}$ and $\mathrm{z}$ coordinate, respectively and $k_{T E}$ is kinetic turbulent energy. $U_{1}$ is defined only with velocity components parallel to the wall. $U^{\prime}{ }_{1}$ is calculated from $k_{T E}$ assuming turbulent velocity in vertical direction from the wall is negligible compared with other two components.

\subsection{Calculation results}

Reference calculation result for fully-developed flow without contraction is shown in Fig. 7. From three velocity conditions, ratio of turbulent velocity to mean velocity was approximately 0.41, which would be the value of $c_{t 2}$ in Eq. (13) and applied in the following evaluation.

Continuously from the calculations with contraction, data at the first cell on the wall surface in contraction downstream were extracted, also. For good agreement between experiment and calculation, intensity factor $c_{t 1}$ was adjusted to obtain streamwize profile of $U_{e}$ similar to averaged FAC rate profile of test specimens in previous report as shown in Fig. 8. In Fig. 9, $U_{e}$ profiles are shown for three velocity conditions obtained by setting $c_{t 1}=3.0$ and $c_{t 2}=0.41$, along with $U_{1}$ and $U^{\prime}{ }_{1}$ profile. In every cases, $U_{e}$ profile showed a peak in region from 10 to 20 mm from contraction, and gradually decreased towards the downstream, which is fairly similar to the profile in Fig. 7.

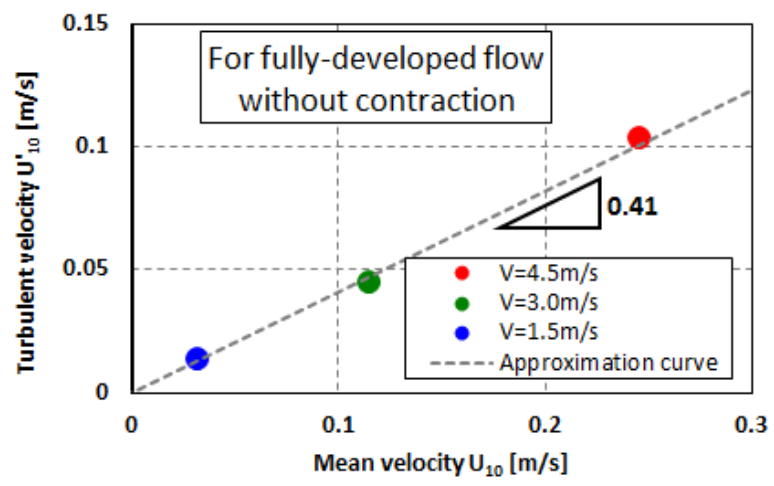

Fig. 7 Correlation of mean and turbulent velocity at $\mathrm{y}_{1}=1.6 \mu \mathrm{m}$ in the flow duct without contraction

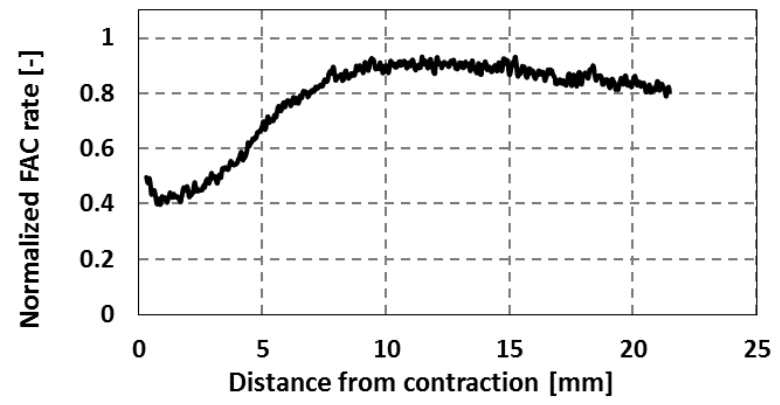

Fig. 8 Averaged FAC rate profile on the test specimen 

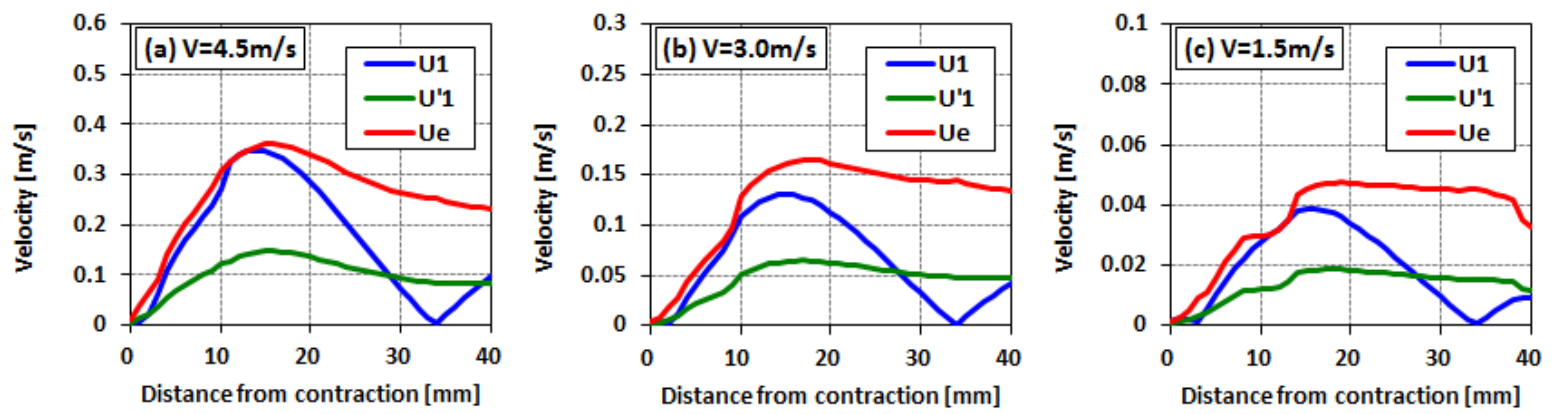

Fig. 9 Streamwize profile of mean, turbulent and effective velocity at $\mathrm{y}_{1}=1.6 \mu \mathrm{m}$

\subsection{Validation results}

FAC prediction method combined with effective mass transfer coefficient is validated with experimental data in this section. FAC test conditions of experimental data from the previous report (Yoneda, 2016) for model validation are shown in Table 1. Three categories are listed in the table; category 1 for neutral pH condition with temperature as parameter, category 2 for alkaline $\mathrm{pH}$ condition as parameter with constant temperature, and category 3 for constant temperature and $\mathrm{pH}$ with velocity as parameter. Test conditions with contraction were chosen to confirm the model performance to predict FAC rate profile of the test specimen. For validation, experimental FAC rate data on the test specimen center line were extracted with $1 \mathrm{~mm}$ pitch from streamwize profile.

To determine exponent $\alpha$ for Reynolds number, impact of hydraulic effect on FAC rate was evaluated according to Eq. (16). Index $n$ was set to 8 according to the Reynolds number condition, exponent $\beta$ for Schmidt number was set to 0.33 as in Eq.(3). Data were plotted with the term in large bracket related to exponent $\alpha$ on R.H.S. of the equation for horizontal axis and normalized FAC rate for vertical axis as shown in Fig. 10. Normalized FAC rate was based on the maximum value with velocity of $4.5 \mathrm{~m} / \mathrm{s}$ for each temperature and $\mathrm{pH}$ condition, which may cancel the effect of water chemistry factors. Although some scattering were seen for few conditions, majority of the data with various temperature, $\mathrm{pH}$ and velocity conditions showed consistent trend with the slope of 0.88 , approximately. Hence, the value of exponent $\alpha$ was determined as 0.88 and applied in the following evaluations.

In Fig. 11, experimental and predicted FAC rate data were compared. In the prediction model, constant $a$ in Eq.(7) was set to 0.0396 as in Eq.(6). Most of the predicted data for category 1 and 2 showed good agreement with the experimental data quantitatively with reasonable error. For the data of category 3 with pH 8.9 condition, FAC rate data were mostly over-predicted since referred experimental FAC rate data, which should have been between the data with pH 8.8 and 9.0, were not originally consistent with category 2 data. However, they were consistent within its own category proving that the evaluation of hydraulic effect from Fig. 10 was valid. Additionally, validity of the setting of exponent $\alpha$ was checked by varying the value around 0.88. In Fig. 12, average prediction error with data scattering range for experimental FAC rate is shown for each value of $\alpha$. Results with $\alpha=0.88$ shows minimum scattering range with reasonable conservativeness which would be essentially important when applied to actual plant pipe management. As a whole, FAC prediction method combined with presented effective mass transfer coefficient was confirmed to predict experimental data of FAC rate, quantitatively.

Table 1 FAC test condition for model validation

\begin{tabular}{|c|c|c|c|c|c|}
\hline Category & Temperature (T) & $\mathrm{pH} @ 25^{\circ} \mathrm{C}$ & Velocity (V) & $\begin{array}{c}\text { Contraction } \\
\text { height }(\mathrm{h})\end{array}$ & Cr content \\
\hline 1 & $50 \sim 150^{\circ} \mathrm{C}$ & 7.0 & $4.5 \mathrm{~m} / \mathrm{s}$ & $3 \mathrm{~mm}$ & 0.001 mass\% \\
\hline 2 & $150^{\circ} \mathrm{C}$ & $8.8 \sim 9.4$ & $4.5 \mathrm{~m} / \mathrm{s}$ & $3 \mathrm{~mm}$ & 0.001 mass $\%$ \\
\hline 3 & $150^{\circ} \mathrm{C}$ & 8.9 & $1.5 \sim 4.5 \mathrm{~m} / \mathrm{s}$ & $3 \mathrm{~mm}$ & 0.001 mass $\%$ \\
\hline
\end{tabular}



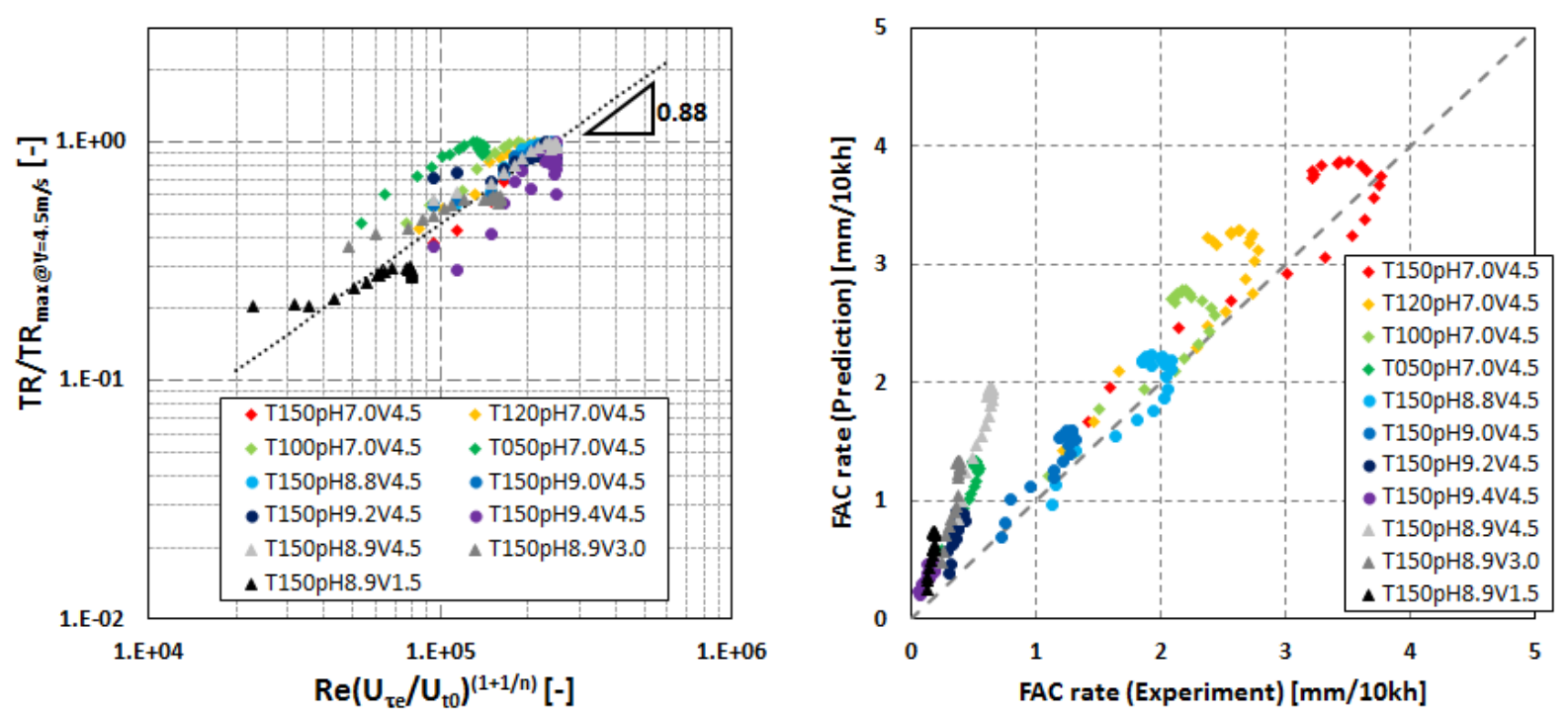

Fig. 10 Impact of hydraulic effect on FAC rate

Fig. 11 Comparison of experimental and predicted FAC rate

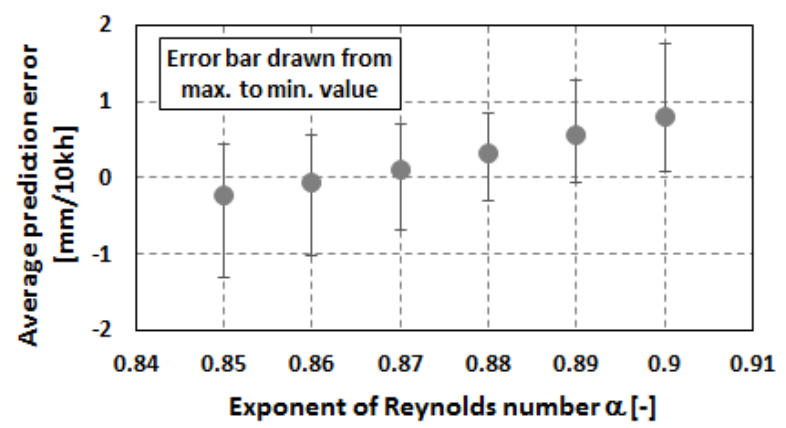

Fig. 12 Prediction error for experimental FAC rate in terms of exponent $\alpha$

\section{Model validation with power plant measurement data 4.1 Subjected power plant data}

In this chapter, FAC prediction model was validated with measurement data obtained from actual power plant pipe components. The pipe component data for validation are listed in Table 2. Although geometry with a flow contraction, somewhat like an orifice, was subjected in experimental FAC rate data validation in chapter 3 , since the presented mass transfer coefficient correlation depends only on general turbulence parameters in a flow field, the most frequently used pipe component in power plants was sampled: i.e. elbows. From four plants, including one BWR and three PWRs, nine elbows were chosen for validation of which five of them in low temperature at $40^{\circ} \mathrm{C}$ with neutral $\mathrm{pH} 7.0$ condition and the rest in rather higher temperature at $150{ }^{\circ} \mathrm{C}$ with alkaline $\mathrm{pH} 9.2$ condition. For some of the elbows, pipe materials were sampled after replacement for chromium content measurement by atomic absorption spectrometry and also for surface observation where typical scallop pattern is confirmed in higher temperature condition as shown in Fig. 13.

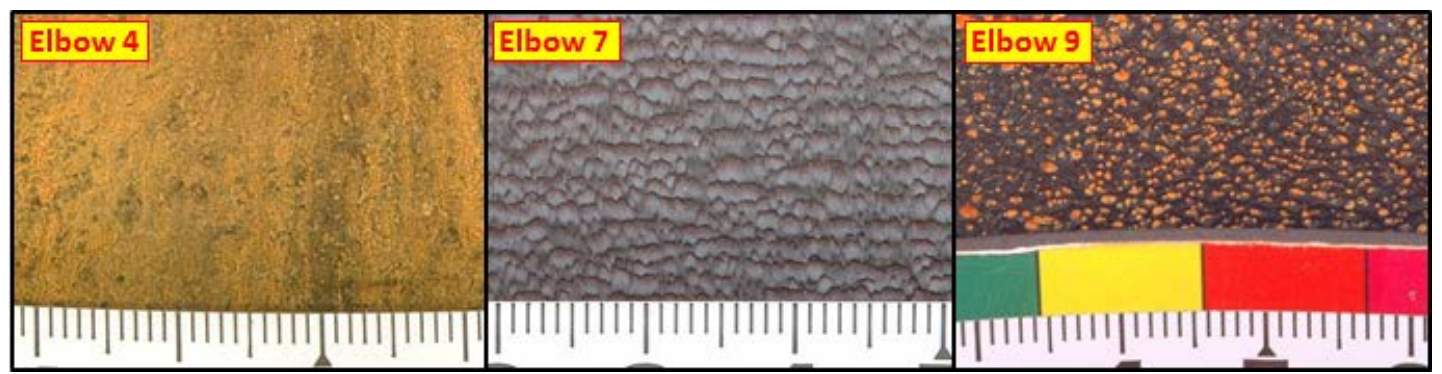

Fig. 13 Examples of pipe surface observation at elbow intrados 
Table 2 Pipe component data for prediction model validation

\begin{tabular}{|c|c|c|c|c|c|c|}
\hline Plant & Piping location & Temperature & Velocity & $\mathrm{pH} @ 25^{\circ} \mathrm{C}$ & Component & Cr content \\
\hline \multirow{3}{*}{ BWR A } & \multirow{3}{*}{$\begin{array}{l}\text { Condensate } \\
\text { demineralizer } \\
\text { downstream }\end{array}$} & \multirow{3}{*}{$40^{\circ} \mathrm{C}$} & \multirow{3}{*}{$3 \mathrm{~m} / \mathrm{s}$} & \multirow{3}{*}{7.0} & Elbow 1 & N.A.* \\
\hline & & & & & Elbow 2 & N.A. ${ }^{*}$ \\
\hline & & & & & Elbow 3 & N.A.* \\
\hline \multirow[b]{2}{*}{ PWR B } & \multirow{2}{*}{$\begin{array}{l}\text { Condensate } \\
\text { demineralizer } \\
\text { downstream }\end{array}$} & \multirow[b]{2}{*}{$40^{\circ} \mathrm{C}$} & \multirow[b]{2}{*}{$3 \mathrm{~m} / \mathrm{s}$} & \multirow[b]{2}{*}{7.0} & Elbow 4 & 0.009 mass $\%$ \\
\hline & & & & & Elbow 5 & 0.009 mass $\%$ \\
\hline \multirow{3}{*}{ PWR C } & \multirow{3}{*}{$\begin{array}{l}\text { LP-Feedwater heater } \\
\text { downstream }\end{array}$} & \multirow{3}{*}{$150^{\circ} \mathrm{C}$} & \multirow{3}{*}{$3 \mathrm{~m} / \mathrm{s}$} & \multirow{3}{*}{9.2} & Elbow 6 & N.A. ${ }^{*}$ \\
\hline & & & & & Elbow 7 & 0.031 mass $\%$ \\
\hline & & & & & Elbow 8 & N.A.* \\
\hline PWR D & Deaerator upstream & $150^{\circ} \mathrm{C}$ & $3 \mathrm{~m} / \mathrm{s}$ & 9.2 & Elbow 9 & 0.011 mass $\%$ \\
\hline
\end{tabular}

*Cr content assumed as 0.01 mass $\%$ for non-measured elbows

To evaluate local effective mass transfer coefficient at subjected components, CFD calculations were conducted for each relevant piping system shown in Fig. 14. As in the case for FAC test geometry, commercial CFD code STAR-CCM+ Ver.4/5 was utilized to obtain flow characteristic data on the wall surface, basically with similar calculation settings; Realizable k- $\varepsilon$ two-layer model for turbulent model, prism layer mesh along the wall, first cell center at less than $1.5 \mu \mathrm{m}$ from the wall. Hexahedral meshes were applied for the calculation model except for a glove valve in PWR C plant model where polyhedral meshes were used for its complex geometry. Number of cells was about 1.1 million, 3.0 million, 7.5 million, and 9.3 million meshes for BWR A, PWR B, PWR C and PWR D, respectively.

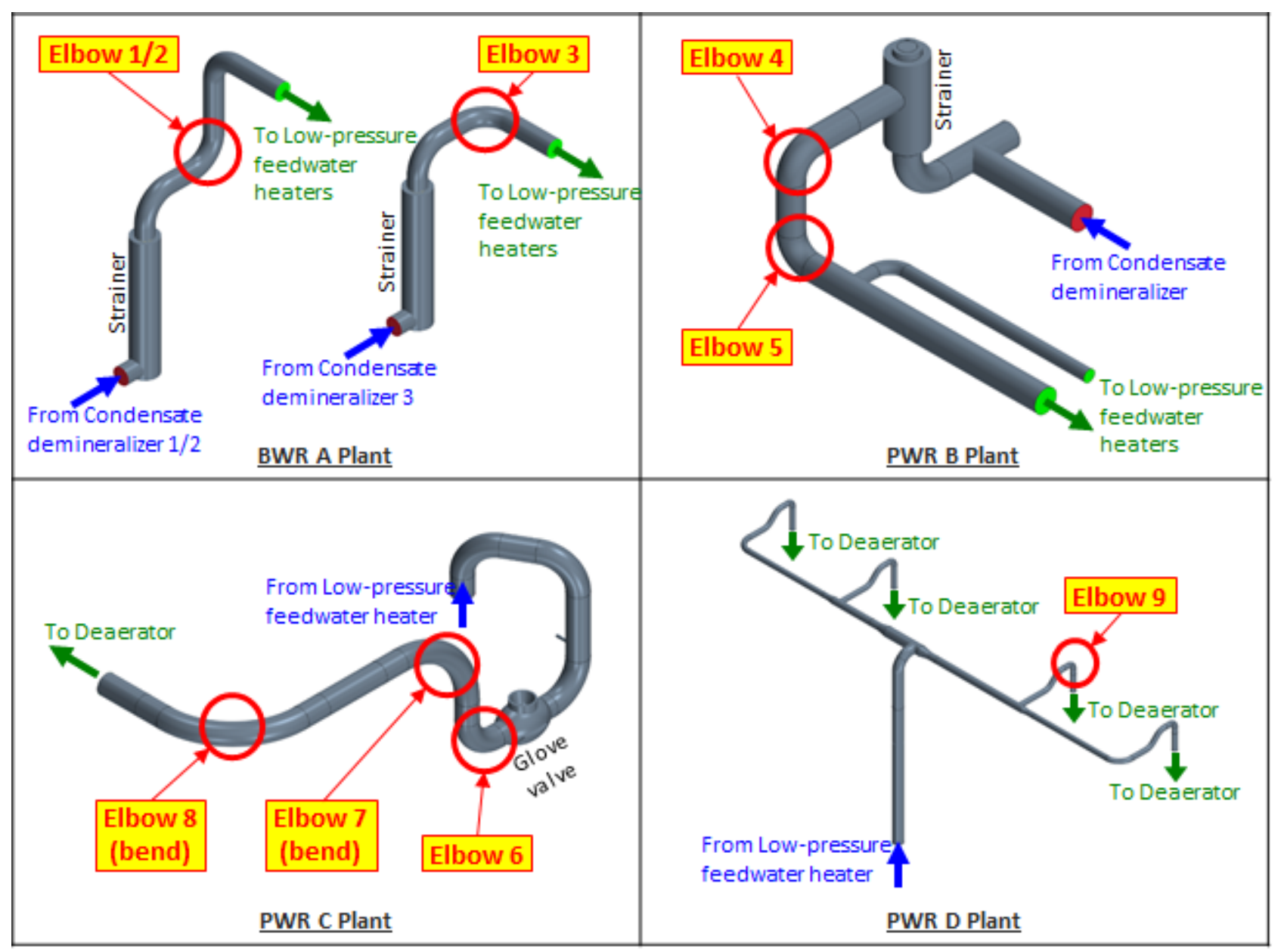

Fig. 14 CFD calculation models for power plant piping 


\subsection{Validation results}

Steady-state flow calculations for each plant piping system were conducted and flow characteristics at the subjected components were obtained. Local effective mass transfer coefficient profile were derived with mean and turbulent velocity data from the calculation results and combined into FAC rate prediction through exactly the same process using same constants described in chapter 3, except for the index $n$ set at 10 according to the Reynolds number in the power plant piping around $10^{6}$ to $10^{7}$ and corresponding constant $\mathrm{C}$ as well.

Predicted FAC rate data were compared with the measurement data of each elbow. For each elbow, measurement data were obtained at five sections in axial direction with 22.5 bending degree interval and eight sections in circumferential direction with 45 degree interval which would be 40 points in total, as shown in Fig. 14. One example of FAC rate profile comparison is shown in Fig. 16. FAC rate data were normalized by the maximum measured value and plotted in the figures. In this case, the measured FAC rate was highest at intrados inlet and decreased towards outlet while the trend was opposite at extrados. The predicted FAC rate showed rather higher values conservatively but agrees well, qualitatively reproducing overall trend.

Measured and predicted FAC rate data for all nine elbows were compared in Fig. 17. The plots were separated by temperature and $\mathrm{pH}$ condition, and as in Fig. 16, FAC rate data were normalized by the maximum measured value among the whole data set, indifferent to temperature and $\mathrm{pH}$ category. It is noted that FAC rate at $40{ }^{\circ} \mathrm{C}$ with $\mathrm{pH} 7.0$ and $150{ }^{\circ} \mathrm{C}$ with $\mathrm{pH} 9.2$ are quite comparable, which is identical to the experimental results obtained in the previous report (Yoneda, 2016). Among the subjected components, predicted FAC rate for elbow 1, 2, 3, 6 and 9 showed relatively good agreement with the measured data, while the other elbows were rather over-predicted. The difference of this prediction trend is mainly due to the measured FAC rate profile where the former mentioned elbows showed qualitatively typical profile with a peak at intrados inlet while the latter elbows showed relatively flat profile and low FAC rate indifferent to the flow field. $93 \%$ of the data were predicted conservatively which would be an important performance when the method is applied to actual power plant pipe management. As a whole, presented FAC prediction method including effective mass transfer coefficient was confirmed to predict measured FAC rate data of power plant pipe component with fairly good accuracy and reasonable conservatism, at least for the subjected temperature and $\mathrm{pH}$ conditions.

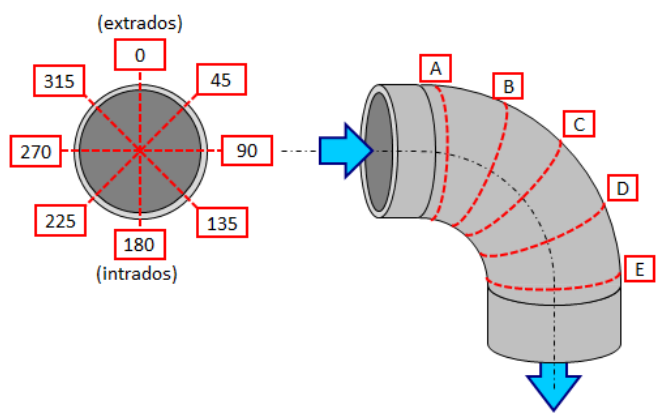

Fig. 15 Measurement points for elbow component
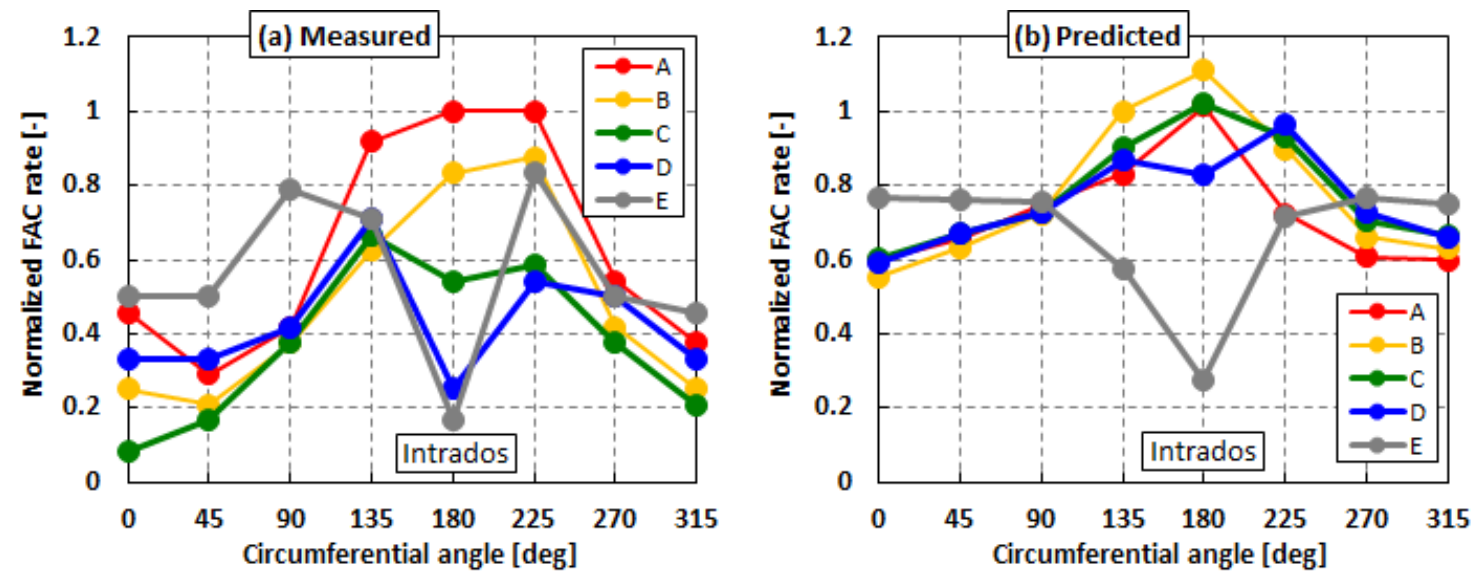

Fig. 16 Example of measured and predicted FAC rate profile for an elbow (PWR D-Elbow9)

(FAC rate normalized by the maximum measured data (max. data in section A)) 

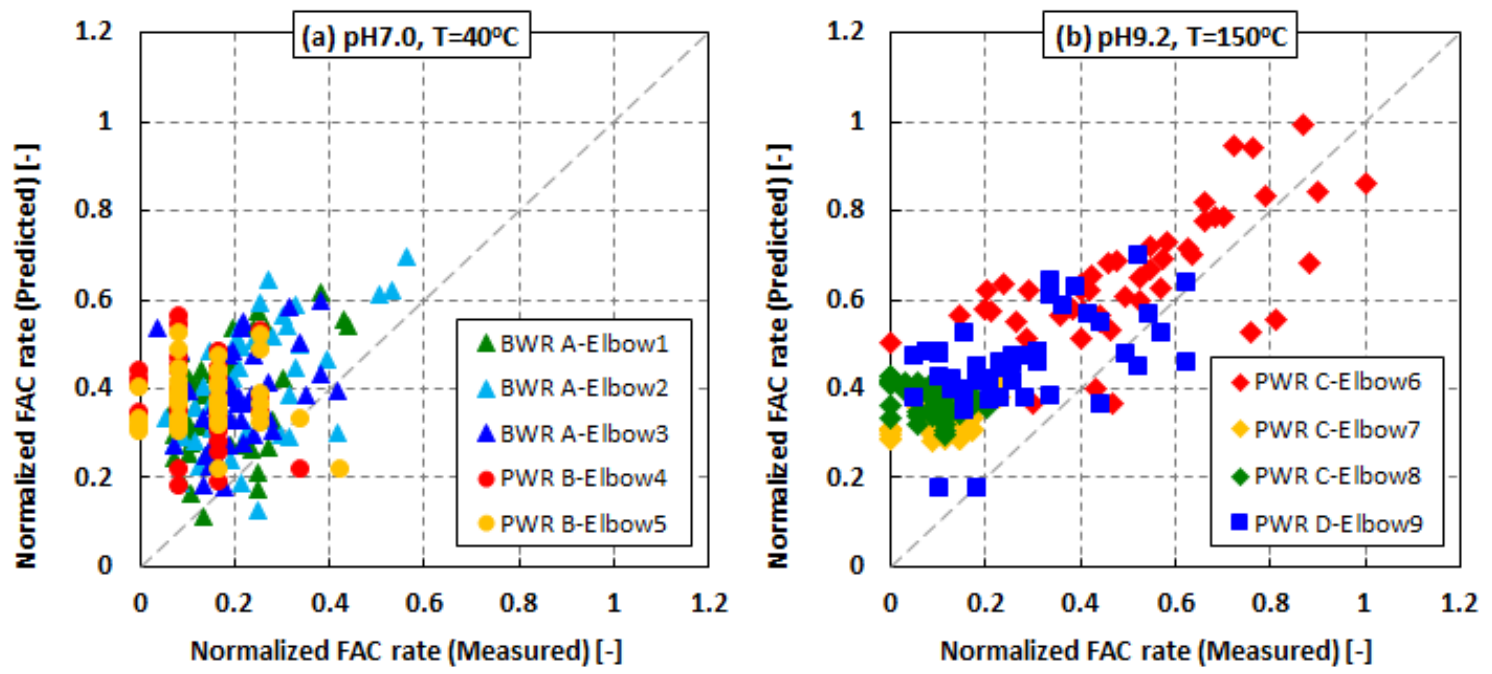

Fig. 17 Comparison of measured and predicted FAC rate for elbows

(FAC rate normalized by the overall maximum measured data (max. data in Elbow 6))

\section{Conclusion}

For prediction of FAC rate profile with eccentric flow condition, effective mass transfer coefficient model was proposed and implemented into the prediction method considering combining effect of local average and turbulent velocity in the near-wall region calculated by CFD simulation code. Fairly good agreement was confirmed between experimental and predicted FAC rate profile, quantitatively. Continuously, prediction method was applied to actual power plant piping systems, and some elbow components were chosen for evaluation in detail. Comparison of measured and predicted FAC rate also showed good agreement with data mostly evaluated conservatively in sense of maintenance management. As a whole, presented FAC prediction method including effective mass transfer coefficient was confirmed to predict measured FAC rate data of power plant pipe component with fairly good accuracy and reasonable conservatism, at least for the subjected temperature and $\mathrm{pH}$ conditions.

\section{Acknowledgements}

The authors are deeply grateful to the Federation of Electric Power Companies of Japan (FEPC) for their continuous support for this study.

\section{References}

Ahmed, W. H., Bello, M. M., Nakla M. E. and Sarkhi, A. A., Flow and mass transfer downstream of an orifice under flow accelerated corrosion conditions, Nuclear Engineering and Design, Vol. 252, pp.52-67 (2012).

Berger, F. P. and Hau, K. -F. F.-L., Mass transfer in turbulent pipe flow measured by the electrochemical method, Int. Journal Meat Mass Transfer, Vol. 20, pp.1185-1194 (1977).

Chexal, B., Recommendations for an effective flow-accelerated corrosion program, EPRI NSAC-202L-R2 (1999).

Chilton, T. H. and Colburn, A. P., Mass transfer (absorption) coefficients: Prediction from data on heat transfer and fluid friction, Industrial and Engineering Chemistry, Vol. 26, pp.1183-1187 (1934).

Electric Power Research Institute, Flow-accelerated corrosion in power plants, TR-106611-R1 (1998).

El-Gammal, M., Ahmed, W. H. and Ching, C. Y., Investigation of wall mass transfer characteristics downstream of an orifice, Nuclear Engineering and Design, Vol. 242, pp.353-360 (2012).

Fujiwara, K., Doumae, M., Yoneda, K. and Inada, F., Model of physic-chemical effect on flow accelerated corrosion in power plant, Corrosion Science, 53, p.3526-3533 (2011). 
Fujiwara, K., Domae, M., Yoneda, K., Inada, F., Ohira, T. and Hisamune, K., Correlation of flow accelerated corrosion rate with iron solubility, Nuclear Engineering and Design, Vol. 241, Issue 11, pp. 4482-4486 (2011).

Fujiwara, K., Yoneda, K. and Inada, F., Effect of dissolved oxygen on flow-accelerated corrosion in neutral and alkaline solutions, EUROCORR, Prague, 78701 (2017)

Lin, C. H. and Ferng, Y. M., Predictions of hydrodynamic characteristics and corrosion rates using CFD in the piping systems of pressurized-water reactor power plant, Annals of Nuclear Energy, Vol. 65, pp.214-222 (2014).

Nuclear and Industrial Safety Agency (NISA) / Ministry of Economy Trade and Industry(METI), Automatic Shutdown of Mihama Power Station Mihama Power Station, Unit-3, Kansai Electric Power Company, Press Release Information (2004).

Persoz, M., Bouvier, J. B., Ardillon, E. and Trevin, S., Analysis of thickness measurements on secondary lines in EDF PWRs to evaluate the accuracy of the flow accelerated corrosion monitoring software: BRT-CICERO, Fontevraud $6^{\text {th }}$ International Symposium, Contribution of Materials Investigations to Improve the Safety and Performance of LWRs, A016-T07 (2006).

Schmitt, G. and Bakalli, M., Advanced models for erosion corrosion and its mitigation, Materials and Corrosion, Vol. 59, No. 2, pp.181-192 (2008).

Shiraishi, T., Watakabe, H., Sato, H., Konomura, M., Yamaguchi, A. and Fujii, T., Resistance and fluctuating pressures of a large elbow in high Reynolds numbers, Journal of Fluids Engineering, Vol. 128, pp. 1063-1073 (2006)

Tagg, D. J., Patrick, M. A. and Wragg, A. A., Heat and mass transfer downstream of abrupt nozzle expansions in turbulent flow, Transactions Institution of Chemical Engineers, Vol. 57, pp.176-181

The Japan Society of Mechanical Engineers (JSME), Codes for Nuclear Power Generation Facilities -Rules on Pipe Wall Thinning Management for PWR Power Plants-, JSME S NG1-2016 (2017).

The Japan Society of Mechanical Engineers (JSME), Codes for Nuclear Power Generation Facilities -Rules on Pipe Wall Thinning Management for BWR Power Plants-, JSME S NH1-2016 (2017).

The Japan Society of Mechanical Engineers (JSME), Codes for Thermal Power Generation Facilities -Rules on Pipe Wall Thinning Management for Thermal Power Plants-, JSME S TB1-2016 (2017).

The Japan Society of Mechanical Engineers (JSME), JSME Mechanical Engineers' Handbook, Fundamentals $\alpha 4$ : Fluid Engineering, pp.69 (in Japanese) (2006)

Tomarov, G. V., A. A. Shipkov, "Simulation of physicochemical processes of erosion-corrosion of metals in two-phase flows," Thermal Engineering, Vol.49, No. 7 pp.530-540 (2002).

United States Nuclear Regulatory Commission (U.S.NRC), Feedwater line break, Information Notice No. 86-106 (1986).

Utanohara, Y., Nagaya, Y., Nakamura, A., Murase, M. and Kamahori, K., Correlation between flow accelerated corrosion and wall shear stress downstream from an orifice, Journal of Power and Energy Systems, Vol. 7, No. 3, pp.138-147 (2013).

Wang, Jianrong and Shirazi, S. A., A CFD based correlation for mass transfer coefficient in elbows, Int. Journal Heat Mass Transfer, Vol. 44, pp.1817-1822 (2001).

Watanabe, S. and Yoneda, K., Evaluation of wall thinning profile by flow accelerated corrosion in separation and union pipe, CRIEPI Report, L12002 (in Japanese) (2013)

Yoneda, K., Morita, R., Fujiwara, K. and Inada, F., Development of pipe wall thinning evaluation method and prediction tool, ASME PVP Conference, Paris, 97601 (2013).

Yoneda, K., Morita, R., Fujiwara, K. and Inada, F., Development of flow-accelerated corrosion prediction method (1) Acquisition of basic experimental data including low temperature condition, JSME Mechanical Engineering Journal, Vol. 3, No. 1, 15-00232 (2016).

Zander, A. and Nopper, H., COMSY software assists lifetime management activities, Transactions of SMiRT 17, Prague, D05-5 (2003). 